Divers@ Revista Eletrônica Interdisciplinar,

Matinhos, v. 14, n. 1, p. 100-112, jan./jun. 2021

ISSN 1983-8921

doi: http://dx.doi.org/10.5380/diver.v14i1.80514

\title{
AGRICULTURA E SUSTENTABILIDADE: MUDANÇAS CLIMÁTICAS E MODIFICAÇÕES NO DESENVOLVIMENTO AGROPECUÁRIO
}

\author{
AGRICULTURE AND SUSTAINABILITY: CLIMATE CHANGE AND MODIFICATIONS IN \\ AGRICULTURAL DEVELOPMENT
}

\author{
Gabrielle de Oliveira Magalhães ${ }^{1}$ \\ Erich dos Reis Duarte ${ }^{2}$ \\ Fernando Zawadzki ${ }^{3}$ \\ Edson Bertolini ${ }^{4}$ \\ Fernanda Neves Paduan ${ }^{5}$ \\ Cristiano Reschke Lajús ${ }^{6}$ \\ Camila Ferreira Miyashiro ${ }^{7}$ \\ Aline Vanessa Sauer ${ }^{8}$
}

\begin{abstract}
Resumo
As mudanças climáticas tornaram-se um dos maiores desafios para ser superado na esfera rural em busca do desenvolvimento sustentável. As consequências dessas mudanças podem afetar não apenas a produtividade no campo, mas também o bem-estar da humanidade que depende dos ecossistemas. Analisar as causas dos impactos proporciona uma visão sistêmica dos fatores e isso ajuda a entender e modificar as ações prejudiciais e criar possíveis soluções de reparação ambiental que mantenha altos índices de produção. Mesmo com tanto impacto gerado pelas mudanças climáticas à agropecuária, existem maneiras que reduzem danos e auxiliam na adaptação às condições climáticas desfavoráveis. O objetivo geral deste trabalho foi identificar como as mudanças climáticas podem modificar o desenvolvimento agropecuário brasileiro. Este trabalho foi elaborado a partir de uma pesquisa bibliográfica, com base de análise em
\end{abstract}

\footnotetext{
* Artigo Original: Recebido em 12/04/2021 - Aprovado em 13/05/2021.

${ }^{1}$ Engenheira Agrônoma, Universidade Pitágoras Unopar, Bandeirantes/PR, Brasil. e-mail: magalhaesgabrielle17@gmail.com ORCID: https://orcid.org/0000-0002-1692-4713 (autor correspondente)

${ }^{2}$ Docente de graduação em Agronomia, Universidade Pitágoras Unopar, Bandeirantes/PR, Brasil. e-mail: erichreis@bol.com. br ORCID: https://orcid.org/0000-0002-7646-3779

${ }^{3} \mathrm{PhD}$ em Zootecnia, Universidade Estadual de Maringá, Maringá/PR, Brasil.e-mail: fernando.zawadzki@hotmail.com ORCID: https://orcid.org/0000-0001-5097-9454

${ }^{4}$ Professor Adjunto A. Faculdade de Agronomia, Universidade Federal do Rio Grande do Sul, Porto Alegre/RS, Brasil. e-mail: edson.bertolini@ufrgs.br ORCID: https://orcid.org/0000-0001-5892-6840

${ }_{5}^{5}$ Docente de graduação em Agronomia/Doutoranda em Agronomia, Universidade Pitágoras Unopar/Universidade Estadual de Londrina, Bandeirantes/PR; Londrina/PR, Brasil. e-mail: f.nevespaduan@gmail.com ORCID: https://orcid.org/0000-00021934-3113

${ }^{6}$ Docente de Graduação em Agronomia, Universidade Comunitária da Região de Chapecó, Chapecó/SC, Brasil. e-mail: clajus@unochapeco.edu.br ORCID: https://orcid.org/0000-0003-3847-9793

${ }^{7}$ Docente de Graduação em Agronomia/Docente em Agronomia em Regime Especial, Universidade Pitágoras Unopar/Universidade Estadual Norte do Paraná, Bandeirantes/PR, Brasil. e-mail: camila.ferreira@kroton.com.br ORCID: https://orcid. org/0000-0003-4397-5222

8 Docente de Graduação em Agronomia/Docente em Agronomia em Regime Especial; Docente do Programa de Mestrado em Agronomia, Universidade Pitágoras Unopar/Universidade Estadual Norte do Paraná, Bandeirantes/PR, Brasil. e-mail: aline. sauer@kroton.com.br ORCID: https://orcid.org/0000-0003-3164-9710
} 
artigos de diversos autores sobre os estudos das condições climáticas, os impactos ambientais e como influenciaram a mudança da vida no campo. Deste modo, é essencial que toda a sociedade, de maneira geral, o que inclui fazendas e cooperativas, realizem a incorporação de uma gestão de riscos consequentes das mudanças climáticas em seus processos de planejamento, onde grande parte disto se associa por identificar a vulnerabilidade atual aos impactos das mudanças climáticas.

Palavras-chave: Adaptação às Condições Climáticas; Desenvolvimento Sustentável; Sistemas Agropecuários.

\begin{abstract}
Climate change has become one of the biggest challenges to be overcome in the rural sphere in search of sustainable development. The consequences of these changes can affect not only productivity in the countryside, but also the well-being of humanity that depends on ecosystems. Analyze the impacts causes provides a systemic view of the factors and this helps to understand and modify the harmful actions and create possible environmental repair solutions that maintain high levels of production. Even with the impact of climate change on agriculture, there are ways to reduce damage and help adapt to unfavorable climatic conditions. The general objective of this work was to identify how climate change can modify the Brazilian agricultural development. This work was elaborated from a bibliographic research, based on analysis in articles of several authors about the studies of climatic conditions, the environmental impacts and how they influenced the change of life in the countryside. Thus, it is essential that the whole society, in general, which includes farms and cooperatives, carry out the incorporation of risk management resulting from climate change in their planning processes, where a large part of this is associated with identifying the current vulnerability the impacts of climate change.
\end{abstract}

Keywords: Adaptation to Climate Conditions; Sustainable Development; Agricultural Systems.

\section{Introdução}

Agropecuária é o termo utilizado para definir as atividades realizadas nas áreas rurais na qual agricultura e a pecuária se agrupam. Neste contexto, agricultura compreende os diversos cultivos e lavouras, incluindo todas as ações que tratam o solo. A grande maioria das atividades agrícolas são relacionadas com a produção de alimentos como verduras, frutas, grãos, entre outros. Em contrapartida, a pecuária baseia-se na criação de animais e a destinação de cada espécie pode ocorrer de diversas maneiras como, por exemplo ovos, diversos tipos de carnes, mel, lã e muitos outros produtos (BÜHLER, 2010; BRASIL, 2000).

Inúmeros são os fatores econômicos e sociais capazes de causar interferências nos resultados da produção agropecuária. Sendo assim, se faz fundamental possuir planejamento estratégico para lidar com possíveis problemas. Porém, as mudanças climáticas tornaram-se um dos maiores desafios a serem superados na esfera rural em busca do desenvolvimento sustentável. As consequências dessas mudanças podem afetar não apenas a produtividade no campo, mas também o bem-estar da humanidade dependente dos ecossistemas que constantemente são drasticamente abalados (LIMA; ALVES, 2008). Devido as mudanças climáticas e seus sérios impactos na agropecuária, todo o meio ambiente poderá sofrer as consequências. As avaliações das circunstâncias geradoras dos impactos climáticos em relação à agropecuária, mostram que metodologias de redução de danos, adaptação as atuais metodologias e projeções das alterações climatológicas crescentes e constantes são extremamente necessárias. Deste modo, poderá compreender-se como desenvolver metodologias de redução aos danos à ambas as partes e se adaptar ao novo ambiente que existirá (FISCHER et al., 2005; GHINI et al., 2007; LIMA; ALVES, 2008).

A preocupação da sociedade com o meio ambiente se destacou nos últimos tempos. O uso desordenado dos recursos naturais evidencia a crise ambiental 
em que o planeta vive. As mudanças climáticas são resultado das interações humanas com o ambiente. $\mathrm{O}$ crescimento populacional afeta todo tipo de recurso natural e quase não pode mais ser prevenido devido sua ocorrência em ritmo acelerado. Mesmo com tanto impacto gerado pelas mudanças climáticas à agropecuária, existem maneiras que reduzem danos e auxiliam na adaptação às condições climáticas desfavoráveis (PAREJO, 2020).

A sustentabilidade dos sistemas agrícolas tem como pilar fundamental o conhecimento. O sucesso dos produtores rurais depende diretamente de pesquisas públicas e da difusão de conhecimentos gerados. Sejam estes conhecimentos obtidos para obtenção da sustentabilidade econômica, seja para a sustentabilidade ambiental ou seja para a sustentabilidade social a longo prazo. Todos os conceitos gerados sobre as mudanças climáticas poderão auxiliar por consequência na busca pelo aumento da produtividade e consequentemente gerar mais alimentos. A agricultura sustentável demanda o enfoque no entendimento integral dos sistemas agropecuários para a gestão dos recursos naturais. Desta forma, os esforços se concentram em gerar conhecimento para desenvolver os espaços produtivos existentes e auxiliar em situações econômicas, sociais e desafios ambientais da sustentabilidade agrícola. A agricultura sustentável baseia-se fundamentalmente em sistemas de planejamento para importantes tomadas de decisões em uma propriedade rural. Portanto os sistemas agrícolas demandam gestão dinâmica da ciência e ainda assistência qualificada para o planejamento e controle integrado tudo o que se produz (IKERD, 1993).

O desenvolvimento sustentável deve prioritariamente considerar a produção de alimentos por meio da extração de recursos naturais, os quais exigem aumento do consumo energético e emissão de poluentes nos processos geradores de energia e principalmente aumento das áreas de cultivo para a produção de alimentos. Repensar a construção do desenvolvimento sustentável através da transformação do modo de se relacionar entre humanos e a natureza se faz necessário e deve ser visto como um novo padrão para a sociedade (NOGUEIRA, 2019).

O objetivo deste trabalho foi identificar como as mudanças climáticas podem modificar o desenvolvimento agropecuário brasileiro. Enquanto os objetivos específicos foram fundamentar a produção agropecuária e seus sistemas; explorar os impactos ambientais causados pelas mudanças climáticas; apresentar metodologias de adaptação às condições climáticas desfavoráveis utilizadas pelo setor agropecuário. O trabalho foi elaborado a partir de pesquisa bibliográfica embasada em análise de artigos, livros, revistas, monografias, documentários, relatórios, periódicos, entre outras fontes de dados consideradas de relevância e confiabilidade. No levantamento bibliográfico priorizou-se os estudos sobre condições climáticas, impactos ambientais e sua influenciar na mudança da vida no campo.

\section{Sistemas de produção}

$\mathrm{O}$ aumento da demanda por alimentos e energia coloca a sociedade global diante da obrigação de se preservar o ambiente. A quantidade limitada de áreas para cultivo de lavouras e pastagens exige muitas pesquisas para aprimorar e desenvolver continuamente a agricultura. A fim de garantir a sustentabilidade da economia, do ambiente, e da agropecuária do país se fazem necessárias inovações tecnológicas com o objetivo de melhorar a produtividade, racionalização do uso de insumos, dos recursos ambientais e dos meios de produção (PAREJO, 2020).

Utilizar a mesma área da propriedade com mais cultivos contribui com a produção de alimentos e ainda preserva o meio ambiente, pois desta forma não há necessidade de avançar em novas áreas, uma vez que a produtividade aumenta dentro da própria área. No passado, o incentivo à abertura de áreas se fez necessário para o avanço e o sustento da produção de alimentos para sociedade, pois ainda não tínhamos, naquele período, tecnologia suficiente para acompanhar a demanda por alimentos. (DUARTE, 2020, p.14).

Um sistema de produção é constituído por um conjunto de sistemas de cultivo e/ou criação ambientados no meio rural, que pode ter a sua definição a partir dos quesitos de produção (terra, capital e mão-de-obra) e integrados através de processos de gestão (CHIAVENATO, 1993). Com base nos conceitos de interatividade e complexidade, alicerce da Teoria Geral de Sistemas - TGS 
(BERTALANFFY, 1973), os sistemas de produção foram classificados pela complexidade e grau de interação entre os sistemas de cultivo e/ou de criação, que formam tais sistemas de produção.

\subsection{Agropecuária}

A agropecuária é um dos setores produtivos e de maior importância em todo o território brasileiro, além de ser assunto recorrente no dia a dia das pessoas. Este setor é constituído pelas atividades rurais de cultivos (agricultura) e de criação de animais (pecuária). Destina-se à produção de suprimentos alimentares tanto para o ser humano quanto para os animais, bem como à produção de matérias-primas de indústrias como as de produção de energia, celulose, têxtil, borracha, entre outras (BÜHLER, 2010).

Os processos produtivos do setor agropecuário envolvem as lavouras, a pecuária e a extração vegetal. Assim como envolvem ainda os processos de agricultura e armazenagem, como as operações de produção agrícola e armazenamento, preparação e distribuição de produtos agrícolas (BRASIL, 2000).

O mundo atualmente é um espaço econômico global e muito competitivo, onde a revolução tecnológica é permanente e contínua, com descobertas científicas e avanços tecnológicos acelerados e significativos, com novos métodos de produção e novos produtos, com muitas cadeias produtivas integradas globalmente. A geração de conhecimento também faz parte de uma cadeia globalizada, a legislação sobre a propriedade intelectual possui um padrão internacional e está sendo normatizada em todos os países, em função de acordos e tratados internacionais (SCOLARI, 2006, p. 21).

Muitas são as atividades agropecuárias e elas podem ser executadas por produtores de qualquer porte. Os tipos de atividades agropecuárias podem ser caracterizadas de acordo com o tipo de trabalho que é realizado no campo pelos produtores, auxiliados por membros de sua própria família ou funcionários.

No intuito de elucidar os procedimentos agropecuários, foram desenvolvidos conceitos sobre os sistemas de trabalho executados em cada setor, que segundo Pessoa (2019), são divididos de acordo com a complexibilidade de cada um em: Agropecuária Intensiva, Agropecuária Intensiva com Mão de Obra e Agropecuária Extensiva.
O principal investimento do setor é a aquisição de terras, ao lado da abertura e do preparo de áreas para exploração econômica. Além da terra, os principais investimentos diretos são em infraestrutura nas propriedades (estradas internas, pontes, armazéns, galpões, entre outros) e maquinário. Dessa forma, a capacidade de produção está diretamente vinculada à área disponível de exploração (GUIMARÃES; PEREIRA, 2014, p. 24).

No setor rural e em relação as plantas e cultivos, a temperatura e a precipitação são os quesitos que mais interferem no crescimento e desenvolvimento das mais variadas espécies. Estes fatores ambientais são capazes de causar perturbação nas composições bioquímicas necessárias para a fotossíntese, afetar os ciclos de cultivo, a qualidade da produção, e causarem ainda outros impactos que alteram de maneiras diferentes cada espécie de cultivo.

A organização dos sistemas agrícolas varia de acordo com cada região do país. Os sistemas são organizados em produção vegetal e/ou animal, com suas peculiaridades e similaridades do local onde se inserem. Através dessa organização os modelos e arranjos produtivos são permitidos e eles descrevam de maneira cuidadosa como são os sistemas de produção que predominam na região (HIRAKURI et al., 2012).

Diante disto, é muito importante que o produtor rural e a população das áreas urbanas busquem recuperar e preservar essa vegetação e denunciem os vândalos que usam suas instituições para agravar a crise ambiental que estabelece a escassez dos recursos naturais. $\mathrm{O}$ produtor rural tem aumentado a produtividade das áreas já cultivadas sem agredir o meio ambiente, por meio de tecnologias e realizando o plantio de até três safras em uma única propriedade, contribuindo para a preservação ambiental e sendo responsável por produtos agrícolas em quase $50 \%$ do mercado mundial. (DUARTE, 2020, p.13)

O sistema agrícola refere-se à organização regional dos diversos sistemas de produção vegetal e/ou animal, que considera as peculiaridades e similaridades desses diferentes sistemas. Essa organização deve permitir a construção de modelos e arranjos produtivos que descrevam da forma mais acurada 
possível, nos sistemas de produção predominantes na região. Já os sistemas agropecuários variam de acordo com o tipo de tecnologia que é utilizada. Entretanto, para classificar estes sistemas não há necessidade de se preocupar com o tamanho da propriedade, da área a ser cultivada ou da quantidade de animais na criação. Neste ramo é essencial analisar o capital disponível para investimento em produção e em tecnologia para cultivo ou criação, bem como o índice de produtividade (FREITAS, 2020).

\subsection{1 agropecuária intensiva}

A agropecuária intensiva visa essencialmente a lucratividade dos proprietários. Extrai o que puder das terras com pouca mão de obra, e o ser humano quase não interfere diretamente. Utiliza ferramentas tecnológicas como equipamentos agrários, sistemas de adequação de solo, beneficiamento de sementes, fertilizantes, agrotóxicos, implementos agrícolas e confinamento de gado (PESSOA, 2019).

Ao conceituar o sistema de agropecuária intensiva, é essencial incluir todos os recursos que existem e estão disponíveis ao redor da área de cultivo. Estes recursos podem ser exemplificados através de regiões que possuem relevos montanhosos que possibilitam a implantação de pastagem, porém cultivos anuais para conservar a forragem acabam se tornando uma tarefa difícil. Além disso, o risco de se baixa produtividade e má qualidade da forragem é grande em relação ao plantio em regiões de relevo favoráveis (NOVO et al., 2009).

\subsection{2 agropecuária intensiva com mão de obra}

A agropecuária intensiva com mão de obra, assim como a agropecuária intensiva, também visa a lucratividade, porém com pouco auxílio tecnológico. Este tipo de agropecuária ocorre principalmente em regiões menos desenvolvidas, e regiões onde o produtor possui sua equipe de trabalhadores que executam tradicionalmente o manejo e o cultivo (PESSOA, 2019).

A maior parte da mão de obra utilizada neste sistema é qualificada. Visto que a utilização de máquinas agrícolas é comum, as pequenas quantidades de trabalhadores dessa modalidade concentram-se em áreas técnicas, de manutenção e operação do maquinário (RIBEIRO, 2020).

\subsection{3 agropecuária extensiva}

A agropecuária extensiva caracteriza-se pela inversão da agropecuária intensiva e da agropecuária intensiva com mão de obra. A agropecuária extensiva não possui auxílio tecnológico e sua produtividade é notavelmente menor. Caracteriza-se pela a prática da agricultura familiar, que utiliza métodos antigos e tradicionais (PESSOA, 2019). Por se tratar de um sistema produtivo que na maioria das vezes possui pouco capital para investimento, as técnicas de produção mais relevantes e atuais geralmente possuem custo elevado e, deste modo, não são empregadas no trabalho (RIBEIRO, 2020).

As vantagens comparativas
tradicionais de países onde o setor
agropecuário representa uma parcela
importante na formação do produto
interno bruto (PIB), apoiadas na
disponibilidade de recursos naturais
(terra e clima), fertilizantes, corretivos,
defensivos agrícolas e mão de obra
barata, importantes no passado recente
na chamada "era da revolução verde",
passam a ter importância secundária.
(SCOLARI, 2006, p. 9).

A partir destes conhecimentos tradicionais muito se aproximou da chamada "exaustão tecnológica". Porém, estas vantagens tradicionais estão desaparecendo em alta velocidade na medida em que surgem novos conhecimentos que, em ritmo acelerado são implantados nas mais variadas cadeias produtivas em muitos países ao redor do mundo. $\mathrm{Na}$ agropecuária os impactos ambientais consequentes das mudanças climáticas geradas pelo aquecimento global podem ser reduzidos com a aplicação de sistemas de manejo adequados para cada área e tipo de cultivo realizado. Uma alternativa viável é realizar a alternância entre cultivos e pastagens que reduzem a utilização intensiva de cada atividade na terra (SCOLARI, 2006).

\section{Impactos ambientais causados pelas mudanças climáticas}

De acordo com a United Nations Framework Convention on Climate Change (UNFCCC) a definição de mudança climática baseia-se em: "uma alteração no clima que se atribui de maneira direta ou indireta às atividades humanas, que alteram a 
composição atmosférica e se soma à variabilidade climática natural como observa-se no decorrer das escalas temporais comparáveis". Essa visão da ênfase de que as mudanças climáticas são em decorrência das forças antropogênicas, enquanto a variabilidade se associa mais claramente aos processos naturais (BARRY; CHORLEY, 2013).

A consequência inexorável do consumo, o lixo, ou os resíduos sólidos, causa prejuízo ao meio ambiente. Inicialmente parece ser um problema eminentemente urbano. Porém, a má destinação desses resíduos e a falta de cuidado com a forma pela qual são descartados contribuem para que eles atinjam córregos e rios, degradando os corpos d'água a jusante dos centros urbanos e, consequentemente, prejudicando a utilização da água das cidades e propriedades rurais. (DUARTE, 2020, p.20).
No entanto mesmo com a dependência dos seres humanos no que se relaciona com às condições da atmosfera, compreender o sistema climático e suas interações é ainda parcial. Essa parcialidade se deve aos processos atmosféricos variarem muito, são sensíveis e de difícil percepção, e ainda em decorrência da complexidade da interatividade entre o sol, atmosfera, oceanos, gelo, relevo, terras emersas, vegetação e os seres vivos (NUNES, 2002).

Segundo Barry e Chorley (2013) a medida mais essencial do estado climático da Terra é a média global anual da temperatura do ar junto à superfície. A Figura 1 mostra as anomalias da temperatura, em média, da superfície terrestre registradas em 2015 em comparação com o período de 1951 à 1980. Pode-se observar que as grandes ondas de calor aconteceram principalmente no hemisfério norte e na América do Sul. No Brasil, a temperatura mostrada para o ano de 2015 foi entre 1 e $2^{\circ} \mathrm{C}$ acima da média de outros países em relação ao período de comparação. As áreas em cinza não possuem dados que sejam suficientes para calcular tais anomalias (SILVA, 2016).

Figura 1 - Anomalias das temperaturas médias anuais para 2015 com relação ao período-base nos anos de 1951 a 1980

Annual J-D 2015

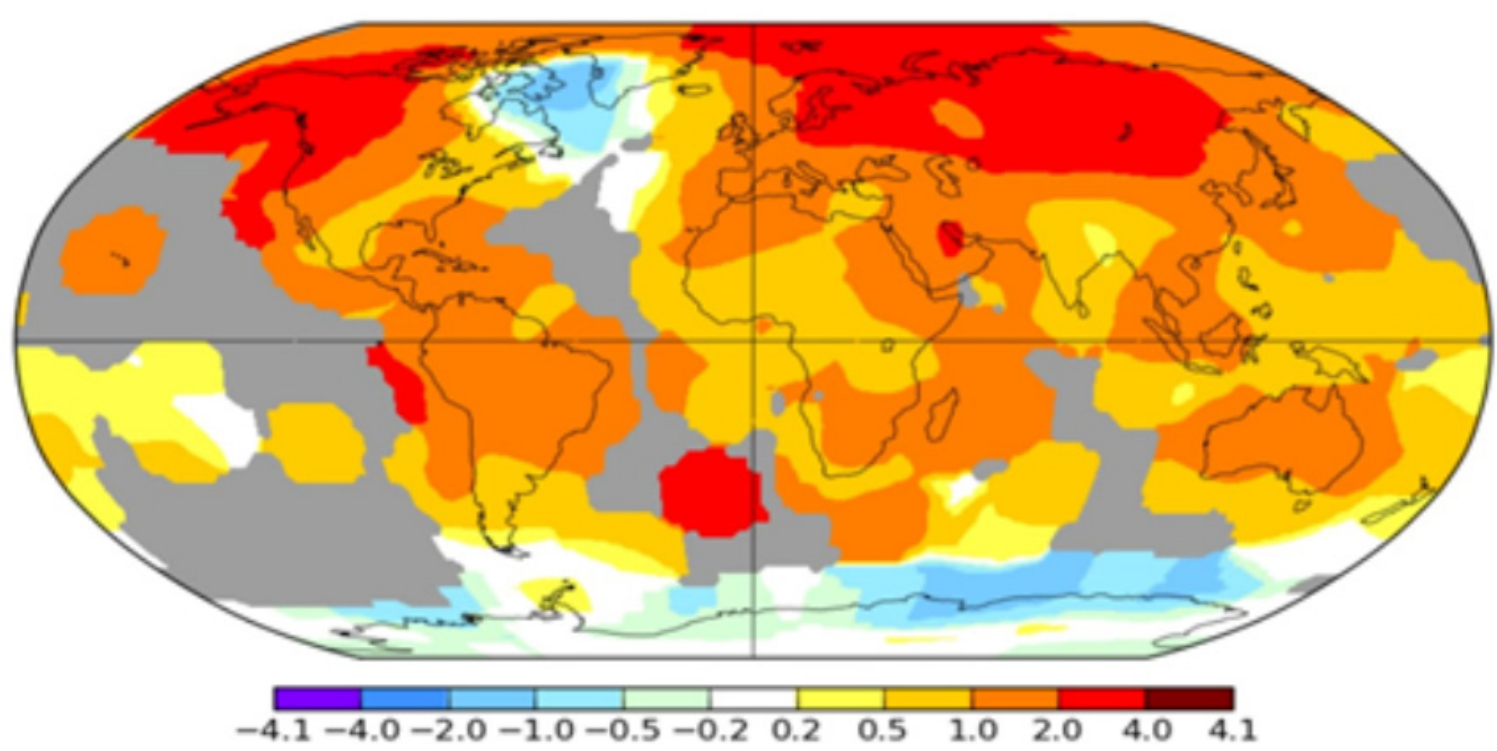

FONTE: Adaptado de Silva (2016). 
As bruscas mudanças na temperatura global, tem sido evidentes em todo o planeta por volta dos últimos 50 anos. Deste modo, são mais frequentes as ondas de calor e frio inesperadas. As precipitações mais fortes também são mais recorrentes, e com intervalos de tempo irregulares, em quase todas as regiões continentais. Assim como as secas por maiores períodos e intensidade, principalmente em regiões de clima tropical e subtropical (IPCC, 2007).

As atividades humanas, principalmente a queima de combustíveis fósseis e o manejo da terra, contribuem de maneira significativa para o aumento da concentração dos gases de efeito estufa na atmosfera, o que altera o balanço radiativo e causa o aquecimento global. Das emissões de gás carbônico para a atmosfera, aproximadamente $97 \%$ são decorrentes de processos naturais. Entretanto, as emissões de carbono por meio das ações humanas giram em torno de 3\%. A partir dessa informação é indiscutível que exista estranhamento, pois é grande o contraste com os discursos de entidades de defesa do meio ambiente, que sempre encontram uma maneira de colocar a culpa nas ações dos seres humanos, ressaltando o seu papel principal no agravamento dos danos ao meio ambiente e nas mudanças climáticas (SEABRA, 2008). Porém, ao mesmo tempo é inegável que o homem ao interagir com a natureza seja capaz de transformá-la drasticamente e que assim a natureza contribuiu ao longo do tempo com a transformação do homem através de sua evolução (NOGUEIRA, 2019).

A mudança nas concentrações dos gases de efeito estufa irão conduzir a mudanças mundiais e regionais nas temperaturas, na precipitação e em outras características do clima, dando origem as modificações nos ecossistemas e o que leva ao aumento do nível dos mares (IPCC, 2007).

As consequências das mudanças climáticas nos ecossistemas dependerão da magnitude e espaço de tempo em que as variações térmicas ocorrerem. A literatura aponta modificações na distribuição de espécies, alterações no metabolismo orgânico e na estabilidade do habitat, alterações na dispersão de nutrientes nas águas e na dinâmica do ciclo hidrológico, bem como na dinâmica dos demais ciclos biogeoquímicos. (RICHIERI, 2006, p. 15).
As projeções dos modelos climáticos (IPCC, 2005) tem previsão de que a temperatura média da superfície terrestre aumente cerca de $1,4^{\circ} \mathrm{C}$ a $5,8^{\circ} \mathrm{C}$ até o ano de 2100 e o nível dos mares aumente de 9 à 88 centímetros. É possível que a velocidade do aquecimento seja maior do que se conhece nos últimos dez mil anos, mesmo que os valores de algumas regiões acabem diferindo da média mundial. Estas mudanças, em longo prazo e em grande escala, decorrentes de atividades antrópicas, terão interação com fenômenos naturais e temporais como, por exemplo, o El Niñoi, influenciando o bem-estar da sociedade e da economia.

Estudos científicos elaborados por inúmeras organizações intergovernamentais apresentam a saúde humana, os ecossistemas e vários setores econômicos encontram-se suscetíveis às variações climáticas, particularmente à grandiosidade e a velocidade que essas mudanças acontecem. Dentre os setores econômicos apresentados nestes estudos enquadram-se como exemplos os recursos hídricos, a produção de alimentos, os sistemas costeiros e os assentamentos humanos, que são essenciais para o desenvolvimento sustentável (RICHIERI, 2006). Além disso, também é preciso levar em consideração que os impactos das mudanças climáticas extremas acabam possuindo maior gravidade na medida em que há maior vulnerabilidade em relação a utilização e à ocupação do solo, seja em áreas rurais ou nas áreas urbanas (LELIS et al., 2011). Essa preocupação envolve todo o
estudo de Impacto Ambiental de áreas
a serem exploradas e áreas que já
estão em atividade, para que permitam
o aumento de produtividade, por
meio de tecnologias como adubação,
biotecnologia e seleção de genética de
qualidade, promovendo aumento de
produtividade de forma sustentável.
(DUARTE, 2020, p. 34).

Em conformidade com a Organização Meteorológica Mundial, a Terra está mais quente do que no período antecessor aos processos industriais. O cenário mundial posterior a Revolução Industrial teve mudanças não apenas na economia, mas também no modo de produzir, o que acarretou em alterações do ambiente (SANTOS, 2020). O exagero no consumo e os altos números de produção, além de gerar elevada taxa de exploração dos recursos naturais, geram também o aumento da poluição 
atmosférica, em consequência da emissão gases poluentes pelas indústrias e automóveis. A produção também aumentou a velocidade do desmatamento, o que ajudou a modificar drasticamente o clima (SANTOS, 2020).

$$
\begin{aligned}
& \text { Os sistemas ecológicos estão } \\
& \text { influenciados constantemente pela } \\
& \text { variação climática, proveniente } \\
& \text { da maior concentração de gás } \\
& \text { carbônico na atmosfera. Se benéficas } \\
& \text { para algumas espécies vegetais, as } \\
& \text { mudanças climáticas podem alterar a } \\
& \text { composição de ecossistemas através } \\
& \text { da proliferação de organismos } \\
& \text { indesejáveis, enfermidades ou } \\
& \text { alterações na cadeia alimentar. } \\
& \text { (RICHIERI, 2006, p. 16). }
\end{aligned}
$$

As inúmeras disciplinas do âmbito científico se desprepararam perante as questões ambientais. Não somente pela compreensão da dinâmica de alguns dos processos naturais, mas também, no relacionamento da alteração desses processos pela ação do homem. Essas alterações acabam retornando à humanidade com um sabor amargo em decorrência de seus efeitos (RICHIERI, 2006).

Em 2018, o Relatório Especial do Painel Intergovernamental sobre Mudanças Climáticas (IPCC) trouxe informações sobre o aumento do aquecimento global em $1,5{ }^{\circ} \mathrm{C}$. Apresentou ainda dados de grande importância que garantem a correta tomada de decisões por parte dos governantes no intuito de evitar que a temperatura aumente de maneira exagerada (SANTOS, 2020). Segundo esse relatório, é fundamental que a temperatura terrestre não aumente mais que $2^{\circ} \mathrm{C}$ acima dos níveis de temperatura anteriores à Revolução Industrial. Esse aumento traria sérias e catastróficas consequências como, por exemplo, a escassez de biodiversidade, a falta de habitat, redução das calotas polares, entre outros. É essencial mudar rapidamente para que o aquecimento do planeta não ultrapasse o $1,5^{\circ} \mathrm{C}$ (SANTOS, 2020).

Problemas como o aumento do nível do mar, ocasionado pela elevação da temperatura e consequente degelo das geleiras. Isso afetará diretamente a população que vive em áreas costeiras em todo o mundo, em razão da submersão desses locais. Além disso, muitos lugares sofrerão com o aumento das enchentes e das tempestades, acentuando, assim, os problemas já existentes de alagamento e deslizamento de terras. Em contrapartida, em outras regiões, o nível de chuva deverá cair, causando grande seca. (SANTOS, 2020, p. 1).

O Brasil é um país de muita vulnerabilidade às mudanças climáticas globais, devido a sua grande extensão territorial. Este fato acaba dificultando as análises de impacto e a criação de políticas públicas que reduzam os impactos ao ambiente e a sociedade. Outro aspecto importante, é a alta taxa populacional que não tem acesso a bens e serviços básicos como educação e saúde. Isso acaba reduzindo a capacidade de proteção e reação às mudanças climáticas (PAREJO, 2020).

O clima mais quente decorrente do aquecimento global, pode causar epidemias fatais e aumento de doenças como malária, dengue e disenteria. Quando as pessoas contaminadas a estas doenças não são submetidas a tratamentos podem acabar morrendo (MUINGA; GALATTO, 2017).

De acordo com as análises aprofundadas de Giddens (2009) o Estado tem papel fundamental ao que diz respeito sobre o desenvolvimento de políticas públicas e questões que se relacionam com as mudanças climáticas, realizando o cumprimento de sua obrigação em facilitar as discussões sobre essa temática, ressaltando:

- $\quad$ O Estado deve se preparar para a adaptação aos impactos das mudanças climáticas, assim como desenvolver políticas de longo prazo.

- O Estado deve incentivar o empenho na prevenção de como e onde os impactos ocorrerão, e agir preventivamente para conter ou minimizar, incentivando a integração de aspectos locais, regionais e internacionais nas políticas para mudança climática.

Segundo Tanaka (2010, p. 27), “... o nível dos mares subiu de 10 a $25 \mathrm{~cm}$ ao longo do século passado e os modelos indicam que vai subir muito mais depressa neste século". Em decorrência disso, os representantes dos governos sofrem cada vez mais pressão das entidades e organizações de defesa do meio ambiente, no intuito de buscarem soluções para as mudanças climáticas. 
É de conhecimento amplo que o clima exerce influência significativa sobre a sociedade, causando efeitos positivos e negativos. Entretanto, foca-se muito mais nos aspectos negativos dos extremos climáticos, por causarem perdas econômicas e até de vidas humanas. (MUINGA; GALATTO, 2017, p. 2).

A sociedade humana está cada vez mais vulnerável às variações climáticas. A vulnerabilidade é a medida pela qual a sociedade é propensa a sofrer em decorrência das mudanças climáticas, pois o clima e suas variações influenciam a vida do ser humano e suas atividades, afetando sua saúde, energia e conforto (AYOADE, 2006). O homem utiliza sua força e intelectual no processo de interação com a natureza para garantir que sua espécie progrida e prospere ao desenvolver condições sociais e culturais de sobrevivência. O desenvolvimento sustentável pode ser uma maneira de repensar a forma na qual a natureza e o homem se unam neste novo tipo de relação para o bem comum (NOGUEIRA, 2019).

\section{Metodologias de adaptação do setor agropecuário às condições climáticas desfavoráveis}

A agricultura e a pecuária são atividades extremamente dependentes das condições climáticas. As bruscas alterações no clima são capazes de afetar a produtividade e o manejo das culturas, assim como os fatores sociais, econômicos e políticos, deste modo, são influenciadas pelas mudanças climáticas globais. Essas influências são específicas a cada cultura e região. As condições de adaptação de propriedades rurais às mudanças do clima são muito variáveis. Podem estar em condições de vulnerabilidade diferentes, em decorrência dos diversos cenários climáticos (LIMA; ALVES, 2008).

A ameaça que as mudanças climáticas globais trazem sobre os setores agrícolas e pecuários se traduzem principalmente em quedas de produtividade, redução das áreas adequadas ao tipo de lavouras e espécies de criação de gado (LIMA; ALVES, 2008). Os países em desenvolvimento são apontados como os mais vulneráveis às alterações climáticas em decorrência de possuir as atividades agropecuárias como predominantes em suas economias. A limitação de capital para tomar medidas de adaptação e a alta exposição dos países em desenvolvimento a condições extremas, assim como a falta de mercados, entre outras condições os colocam na lista de vulnerabilidade (FISCHER et al., 2005).

A natureza pública da proteção ambiental é reconhecida pela Constituição Federal. Os proprietários rurais devem respeitar e utilizar de forma sustentável os recursos naturais, pois são "de uso comum do povo", ainda que estejam dentro de uma propriedade particular. Portanto, a natureza pública da proteção ambiental determina que o interesse público deve sobrepor-se ao privado, na medida em que a todos interessa o desenvolvimento sustentável, determinante para a manutenção das futuras gerações. (DUARTE, 2020, p. 43).

A produção de alimentos utiliza mais de $50 \%$ da biocapacidade do planeta. A melhor e mais vigorosa forma de influenciar a sustentabilidade é a compreensão da sociedade na produção de alimentos (WACKERNAGEL et al., 2019). O IPCC (2007) sinalizou grandes probabilidades de ocorrência da degradação dos recursos naturais como, por exemplo, o solo e a água, em consequência das mudanças nas temperaturas e pela pluviosidade impactando negativamente na agropecuária. Existe também a projeção da diminuição de produtividade de diversas culturas, mesmo quando levando em consideração os efeitos diretos das concentrações dobradas de $\mathrm{CO}_{2}$ e da implantação de medidas para a adaptação moderadas ao nível de fazendas.

Os efeitos de enriquecimento de $\mathrm{CO}_{2}$ podem ser positivos em algumas espécies de plantas assim como a melhora na eficiência da utilização da água. No entanto, em cenários onde o aumento das temperaturas é crescente, este efeito pode ser anulado em decorrência dos impactos das variações climáticas (IPCC, 2007).

Incertezas permanecem como desafios para a elaboração de futuros cenários, como a magnitude e a persistência dos efeitos de crescentes concentrações de $\mathrm{CO}_{2}$ sobre a produção agrícola sob condições realísticas de produção, as mudanças potenciais nas perdas de produção por doenças de plantas e animais, a variabilidade espacial 
nas respostas à mudança do clima, os efeitos de mudanças na variabilidade climática e eventos extremos sobre a agropecuária. (LIMA; ALVES, 2008, p. 2).

A faixa da capacidade de adaptação fisiológica de espécies vegetais é muito grande, o que fornece considerável capacidade de efeito tampão contra as variações associadas às mudanças climáticas. Em contrapartida, há a necessidade de ampliação dos conhecimentos sobre os potenciais e os limites de cada sistema de produção às mudanças climáticas (LIMA; ALVES, 2008). Os principais fatores fisiológicos vegetais que se relacionam com as mudanças climáticas são as vias de assimilação de carbono, a tolerância ao estresse em decorrência das elevadas temperaturas e períodos de estiagem, e o fotoperíodo, que possui grande importância em casos nos quais se fazem necessário migrar as lavouras para outras latitudes. O tipo de solo, levando em consideração as suas características de estocagem de umidade, drenagem e risco à erosão, bem como manejo, também precisam ser considerados (GHINI et al., 2007; LIMA; ALVES, 2008).

Ghini et al. (2007) realizou a identificação de algumas ações que se destinam à adaptação dos setores agrícolas e pecuários às mudanças climáticas como, por exemplo:

- Formulação de mecanismos de apoio aos produtores de modo a auxiliá-los à adaptar-se à mudança do clima;

- Manutenção de uma ampla base genética para culturas e desenvolvimento de variedades de culturas e raças de animais mais tolerantes à seca;

- Melhoramento da resiliência de ecossistemas agrícolas pela promoção de práticas agroflorestais que utilizem e mantenham a diversidade biológica;

- Melhorar a eficiência de uso da água e recarga de água subterrânea pela agricultura conservacionista;

- Apoiar sistemas de pastagem e outros sistemas de produção animal, com atividades voltadas à produção de suplementos alimentares, serviços veterinários, e de suprimento de água, entre outras medidas.
Existem algumas estratégias voltadas para a adaptação dos sistemas agropecuários no Brasil, levando em consideração o atual estágio de conhecimento obtido.

\subsection{Zoneamento agroclimatológico}

O zoneamento agroclimatológico é realizado através da compilação de dados sobre clima, possíveis de serem obtidos através de levantamentos em escalas regionais, contendo informações sobre temperatura e água essenciais para bom desenvolvimento dos cultivos. Essas informações possibilitam a geração de estimativas sobre os riscos de produção de cada cultivo, orientando como melhor utilizar os solos. Essa ferramenta tem grande importância na identificação das melhores áreas para cada tipo de cultivo, otimizando as produtividades, também na identificação de áreas vulneráveis às mudanças climáticas, bem como as áreas mais apropriadas para cada tipo de cultivo em decorrência do regime de chuvas e temperatura (GHINI et al., 2007; LIMA; ALVES, 2008).

Isso nos põe diante da necessidade de fazer algumas considerações sobre o desenvolvimento sustentável, em que o sustentável tem fundamentos constitucionais, pois o art. 225, quando impõe ao Poder Público e à coletividade o dever de defender e preservar o direito ao meio ambiente ecologicamente equilibrado para as presentes e futuras gerações, está precisamente dando o conteúdo essencial da sustentabilidade (DUARTE, 2020, p. 60).

\subsection{Melhoramento vegetal}

A temperatura e a quantidade de chuvas são as principais variáveis climáticas que impactarão na agricultura global em decorrências das mudanças climáticas. O melhoramento vegetal é o ponto principal para adaptar as culturas às condições de estresse, que irão acontecer com mais intensidade nos cenários do futuro. Algumas espécies de plantas possuem tolerância às secas prolongadas. Estas espécies podem possuir genes que irão garantir a termotolerância como ocorre em algumas espécies de feijão, em especial os que são cultivados na região nordestina. O mapeamento desses genes e o desenvolvimento de metodologias irão permitir sua transferência são os principais objetivos das pesquisas do futuro (WAHID et al., 2007). 
Estudos que envolvem a seleção de espécies de rizóbios, microrganismos capazes de nodular e fixar nitrogênio em condição de altas temperaturas, já permitem o isolamento de estirpes com eficiência no feijoeiro (HUNGRIA; VARGAS, 2000). Além das altas temperaturas impactarem negativamente, a seca é um dos estresses ambientais que mais pode afetar a produtividade das culturas em todo o mundo. Entretanto, o simples melhoramento das culturas para altas produtividades em condições livres do estresse hídrico, permitem que as produtividades sejam maiores quando as culturas passam por situações de estresse mais leves e moderadas (CATTIVELLI et al., 2008).

\subsection{Manejo de culturas e solos}

Enquanto são realizados muitos esforços com o intuito de melhorar as condições para que as plantas tenham maior tolerância à períodos anormais, com altas temperaturas e estiagem, o manejo dos sistemas de produção pode ter grande contribuição de maneira imediata no alívio dos problemas. Em sistemas de produção muito simplificados como a monocultura, há baixo aproveitamento dos recursos disponíveis - água, luz, nutrientes, entre outros, o que exige do produtor rural práticas mais intensivas de manejo para que haja condições de desenvolvimento da lavoura. Existem diversas formas de diversificar o sistema de produção e melhorar o aproveitamento dos recursos disponíveis. A diversificação pode consistir na consorciação de culturas, rotação de culturas ou até mesmo em sistemas complexos como agrossilvicultura onde há convivência de espécies florestais nativas e plantas de interesse comercial (EHLERS, 2009).

A cultura do café, por exemplo, é muito sensível a mudanças na temperatura, e segundo Assad et al (2004), mais de 90\% das áreas hoje utilizadas pela lavoura de café estariam comprometidas com uma elevação de cerca de $6^{\circ} \mathrm{C}$ na temperatura média do ar. Uma possibilidade para atenuar este processo é a utilização de sistemas sombreados, tal como é feito na Costa Rica (LIMA; ALVES, 2008, p. 28).

No sistema de rotação de culturas ocorre a alternância de espécies vegetais em determinado espaço de tempo, na mesma área e na mesma estação do ano. Essa prática contribui economicamente com o produtor rural tendo em vista que auxilia no controle de plantas daninhas, pragas e doenças. Além disso, essa prática promove o aumento de matéria orgânica disponível no solo, evita a exaustão do solo e melhora suas características físicas, químicas e também biológicas (EHLERS, 2009).

O consorciamento de distintas espécies também ajuda a criar habitats para os inimigos naturais das pragas, bem como hospedeiros alternativos para as mesmas. Isso ajuda na prevenção de pragas evitando sua proliferação entre indivíduos da mesma espécie, que ali se encontram relativamente isolados uns dos outros. Sempre que duas ou mais espécies são intercaladas, as interações resultantes podem ter efeitos mutuamente benéficos, reduzindo efetivamente a necessidade de insumos externos. Nas consorciações e nas rotações de culturas, os recursos disponíveis - água, nutrientes, luz, entre outros são utilizados de forma mais eficiente. Aliadas ao retorno de matéria orgânica ao solo, esses sistemas contribuem para manter sua estrutura física, ajudam a reduzir a erosão e, consequentemente, melhoram a fertilidade dos solos. A combinação desses fatores leva, invariavelmente, a aumentos de produtividade das lavouras (EHLERS, 2009, p. 42).

Sob a copa das árvores as temperaturas são mais amenas. Isso colabora para diminuir riscos de perdas em produtividade decorrentes de altas temperaturas. A arborização é uma estratégia geradora de benefícios para sistemas de produção de grãos e de pastagens. Outro sistema de gera grandes impactos na economia de água do solo é o plantio direto. Este sistema é utilizado em quase metade da área de produção de grãos no país, e caracterizase pela ausência de movimentação do solo para a semeadura, e por isso fica coberto por resíduos de colheita. O plantio direto passou a ser utilizado para a substituição dos sistemas convencionais de preparo do solo com o intuito de contenção do escorrimento superficial da água (run-off) que lava consigo boa parte do solo, gerando o que se chama de erosão. O plantio direto pode acabar reduzindo em aproximadamente $20 \%$ a perda de água em decorrência do escorrimento, pois a velocidade de escorrimento é devido a existência de resíduos sobre o solo (MARIA, 1999; CERRI et al., 2007).

Além disso, a presença de resíduos sobre a superfície do solo diminui a evaporação e relativamente mais água fica disponível para as plantas (SILVA et al., 2006), aumentando as chances da lavoura superar períodos de estiagem. No Brasil, estima-se que esta prática seja atualmente adotada 
em mais de 20 milhões de hectares, principalmente nas Regiões Sul e Centro-Oeste (CERRI et al., 2007).

\section{Conclusões}

Se faz essencial estudar sobre os impactos decorrentes das mudanças climáticas sobre a agropecuária, visando a minimização das perdas na produtividade e da qualidade das culturas e criações, o que ajuda a escolher quais são as melhores estratégias para diminuir os problemas.

Existe a evidente necessidade de que as unidades de pesquisa estejam integradas e que realizem os esforços necessários para concentrar e gerar conhecimentos sobre a previsão dos impactos das mudanças climáticas sobre a agropecuária do Brasil, analisando quais medidas podem ser tomadas para mitigar e/ou adaptar os cultivos e as criações.

A busca do desenvolvimento sustentável exige habilidade para equilibrar a relação entre preservação dos recursos naturais e desenvolvimento econômico. Também se deve começar a valorizar a economia dos recursos naturais e preservar a biodiversidade, não só as áreas de preservação permanentes, mas também a fauna, o ar, a água e o solo.

Deste modo, é primordial que a sociedade de maneira geral, o que inclui fazendas e cooperativas, realizem a incorporação de uma gestão de riscos consequentes das mudanças climáticas em seus processos de planejamento, onde grande parte disto se associa por identificar a vulnerabilidade atual aos impactos das mudanças climáticas.

\section{Referências}

ASSAD, E. D.; PINTO, H. S.; ZULLO JUNIOR, J; ÀVILA, A. M. H. Impacto das mudanças climáticas no zoneamento agroclimático do café no Brasil. Pesquisa Agropecuária Brasileira, v. 39, n. 11, p.1057-1064, 2004.

AYOADE, J. O. Introdução à climatologia para os trópicos. Rio de Janeiro: Editora Bertrand Brasil, 2006.

BARRY, R. G.; CHORLEY, R. J. Atmosfera, Tempo e Clima. 9. ed. Porto Alegre: Bookman, 2013.

BERTALANFFy, L. V. Teoria Geral dos Sistemas. Petrópolis: Vozes, 1973.

BRASIL. Ministério da Educação - MEC. Referências Curriculares Nacionais da Educação
Profissional de Nível Técnico - Agropecuária. Brasília, 2000. Disponível em: <http://portal.mec. gov.br/setec/arquivos/pdf/agropec.pdf $>$

BÜHLER, O. D. Manual de Administração de Agronegócios. Paranavaí: Universidade Estadual do Paraná - UEPR, 2010.

CATTIVELLI, L.; RIZZA, F.; BADECK, F. W.; MAZZUCOTELLI, E.; MASTRANGELO, A. M.; FRANCIA, E.; MARÈ, C.; TONDELLIA, A.; STANCA, A. M. Drought tolerance improvement in crop plants: An integrated view. Field Crops Research, v. 105, n. 1-2, p. 1-14, 2008.

CERRI, C. E. P.; SPAROVEK, G.; BERNOUX, M.; EASTERLING, W. E.; MELILLO, J. M.; CERRI, C. C. Tropical agriculture and global warming: impacts and mitigation options. Scientia Agricola, v. 64, n. 1, p. 83-99, 2007.

CHIAVENATO, I. Introdução à Teoria Geral da Administração. 4. ed. São Paulo: Makron Books, 1993.

DUARTE, E. R. Legislação ambiental no meio agrícola. São Paulo: Editora Lux, 2020.

EHLERS, E. O Que É Agricultura Sustentável. São Paulo: Editora Brasiliense, 2009.

FISCHER, G.; SHAH, M.; TUBIELLO, F. N.; VELHUIZEN, H. Socio-economic and climate change impacts on agriculture: na integrated assessment, 1990-2080. Philosophical Transactions of the Royal Society, v. 360, n. 1463, p. 2067-2083, 2005.

FREITAS, E. Agropecuária Extensiva e Intensiva. 2020. Disponível em $<$ https://mundoeducacao.uol. com.br/geografia/agropecuaria-extensiva-intensiva. htm>

GHINI, R.; HAMADA, E.; GONÇALVES, R. R. V.; GASPAROTTO, L.; PEREIRA, J. C. R. Análise de risco das mudanças climáticas globais sobre a sigatoka-negra da bananeira no Brasil. Fitopatologia Brasileira, v. 32, n. 3, p. 197-204, 2007.

GIDDENS, A. The Politics of Climate Change. Cambridge: Polity Press, 2009.

GUimarães, D. D.; Pereira, J. P. O. Panorama Setorial 2015-2018 - Agropecuária. Rio de Janeiro: BNDES, 2014. Disponível em: <https://web.bndes. gov.br/bib/jspui/handle/1408/14158>

HIRAKURI, M. H.; Debiasi, H.; Procópio, S. O.; Franchini, J. C.; Castro, C. Sistemas de Produção: Conceitos e Definições no Contexto Agrícola. Londrina: EMBRAPA, 2012.

HUNGRIA, M., VARGAS, M. A. T. Environmental factors affecting $\mathrm{N}_{2}$ fixation in grain legumes in the 
tropics, with an emphasis on Brazil. Field Crops Research, v. 65, n. 2-3, p. 151-164, 2000.

IKERD, J. E. The need for a system approach to sustainable agriculture. Agriculture, Ecosystems and Environment, v. 46, n. 1, p. 147-160, 1993.

IPCC. Special report on safeguarding the ozone layer and the global climate system: issues related to hydrofluorocarbons and perfluorocarbons. Cambridge: Cambridge University Press, 2005.

IPCC. New climate scenarios. Cambridge: Cambridge University Press, 2007.

LELIS, T. A.; CALIJURI, M. L.; FONSECA, A. S.; LIMA, D. C. Impactos causados pelas mudanças climáticas nos processos erosivos de uma bacia hidrográfica: Simulação de cenários. Ambi-Água, v. 6, n. 2, p. 282-294, 2011.

LIMA, M. A.; ALVES, B. J. R. Vulnerabilidades, impactos e adaptação à mudança do clima no setor agropecuário e solos agrícolas. Parcerias Estratégicas, v. 13, n. 27, p. 73-111, 2008.

MARIA, I. C. Erosão e terraços em plantio direto. Viçosa: Sociedade Brasileira de Ciência do Solo, 1999.

MUINGA, N. M.; GALATTO, S. L. Mudanças Climáticas Globais e seus impactos no Meio Ambiente. Geografia em Questão, v. 10, n. 2, p. 121124, 2017.

NOGUEIRA, C. Contradictions in the concept of sustainable development: $\mathrm{Na}$ analysis in social, economic, and political contexts. Environmental Development, v. 30, n. 1, 129-135, 2019.

NOVO, A. L. M.; CAMARGO, A. C.; MENDONÇA, F. C.; BERGAMASCHI, M. A. C. M. Sistema Intensivo de Produção de Leite em Pastagens Tropicais. Circular Técnica 59. São Carlos: EMBRAPA, 2009.

NUNES, L. H. Aproximações sobre mudanças climáticas globais. Terra Livre, v. 1, n. 1), p. 179$184,2002$.

PAREJO, L. C. Mudanças climáticas - Impacto do aquecimento global no Brasil. 2020. Disponível em: $<$ https:/educacao.uol.com.br/disciplinas/geografia/ mudancas-climaticas-impacto-do-aquecimentoglobal-no-brasil.htm>
PESSOA, G. Agropecuária: o que é, tipos de Sistemas e mais. 2019. Disponível em: <https:// www.stoodi.com.br/2019/08/12/agropecuaria-oque-e/>

RIBEIRO, A. Agricultura Intensiva e Extensiva. 2020. Disponível em $<$ https://brasilescola.uol.com. br/geografia/agricultura-intensiva-extensiva.htm>

RICHIERI, S. M. M. Estudo do impacto das mudanças climáticas globais nos mangues tropicais. 117 f. Dissertação (Mestrado em Engenharia de Processos Químicos e Bioquímicos) Escola de Engenharia Mauá do Centro Universitário do Instituto Mauá de Tecnologia, São Caetano do Sul, 2006.

SANTOS, V. S. Mudanças climáticas. 2020. Disponível em: <https://brasilescola.uol.com.br/ biologia/mudancas-climaticas.htm>

SCOLARI, D. D. G. Produção Agrícola Mundial: O Potencial do Brasil. Brasília: EMBRAPA, 2006

SEABRA, G. Terra: mudanças ambientais globais e soluções locais. João Pessoa: Editora Universitária da UFPB, 2008.

SILVA, F. A. M.; PINTO, H. S.; SCOPE, E.; CORBEELS, M.; AFFHOLDER, F. Dinâmica da água nas palhadas de milho, milheto e soja utilizadas em plantio direto. Pesquisa Agropecuária Brasileira, v. 41, n. 5, p.717-724, 2006.

SILVA, K. K. Impactos das mudanças climáticas sobre a demanda de água para irrigação na bacia hidrográfica do rio Ijuí, RS. $55 \mathrm{f}$. Trabalho de Conclusão de Curso (Graduação em Engenharia Ambiental e Sanitária) - Universidade Federal de Pelotas, Pelotas, 2016.

TANAKA, S. Mudanças climáticas. São Paulo: Edições SM, 2010.

WACKERNAGEL, M.; LIN, D.; EVANS, M.; HANSCOM, L.; RAVEN, P. Defying the Footprint Oracle: Implications of Country Resource. Sustainability, 11 (7), 2164. 2019. doi: 10.3390/ su11072164

WAHID, A.; GELANI, S.; ASHRAF, M.; FOOLAD, M. R. Heat tolerance in plants: An overview. Environmental and Experimental Botany, v. 61, n. 3, p. 199-223, 2007.

\footnotetext{
${ }^{i}$ Fenômeno de atuação oceano-atmosférica que se origina no Pacífico tropical, influenciando o clima regional e global, principalmente ecossistemas tropicais.
} 